\title{
Effects of low-molecular-weight polyols on the hydration status of the light-harvesting complex 2 from Rhodobacter sphaeroides 2.4 .1
}

\author{
Ying Shi ${ }^{1}\left[\right.$ Jie Yu ${ }^{3} \cdot$ Yu-Chen Liu ${ }^{4} \cdot$ Peng Wang ${ }^{2} \cdot$ Jian-Ping Zhang ${ }^{2}$
}

Received: 5 February 2021 / Accepted: 20 April 2021 / Published online: 28 April 2021

(C) The Author(s), under exclusive licence to European Photochemistry Association, European Society for Photobiology 2021

\begin{abstract}
Low-molecular-weight (MW) polyols are organic osmolytes influencing water activity. We have investigated the effects of polyol molecules (glycerol and sorbitol) on the optical and triplet excitation dynamics of light-harvesting complex 2 (LH2) from Rhodobacter (Rba.) sphaeroides in buffer-detergent solutions. The resonance Raman spectroscopy demonstrated that, on increasing glycerol and sorbitol volume fractions ranging from 0 to $80 \%(\mathrm{v} / \mathrm{v})$ (accompanied by the decreasing water activities), the planar and all-trans conformation of carotenoids (Crts) remained unchanged, and the bacteriochlorophyll a (BChl) $Q_{\mathrm{y}}$ absorption intensity decreased. The B850 fluorescence amplitude elevated in the $20-80 \% \mathrm{v} / \mathrm{v}$ sorbitol and $20-40 \%$ $\mathrm{v} / \mathrm{v}$ glycerol solution, but decreased in $80 \% \mathrm{v} / \mathrm{v}$ glycerol solution. The change of ${ }^{3}[\mathrm{Crt} *-\mathrm{BChl}]$ interaction bands caused by ${ }^{3} \mathrm{Crt} *-\mathrm{BChl}$ interaction had no obvious correlation with water activities against polyol volume fractions, which are rationalized by the water activity sensitive of $\mathrm{C}$ - and $\mathrm{N}$-termini of protein which binding with $\mathrm{BChls}$. The results suggest that $R b a$. sphaeroides LH2 is more sensitive to low-molecular-weight polyols compared with that of the thermophiles purple bacterium Thermochromatium (Tch.) tepidum we had investigated before.
\end{abstract}

\section{Graphic abstract}



The C- and N-termini of protein, which binding with $\mathrm{BChls}$ are sensitive to water activity change.

Keywords Rhodobacter sphaeroides $\cdot$ Hydration $\cdot$ Glycerol $\cdot$ Sorbitol $\cdot$ Triplet excited state

\section{Introduction}

Ying Shi

shiying@bttc.edu.cn

Extended author information available on the last page of the article
The peripheral light-harvesting complexes 2 (LH2) and the core light-harvesting complexes 1 (LH1) are encircling reaction centers (RC) arrangement orderly in the intracytoplasmic membranes (ICMs) of photosynthetic purple bacteria. These membrane proteins can harvest and utilize light 
efficiently by the cascading $\mathrm{LH} 2 \rightarrow \mathrm{LH} 1 \rightarrow \mathrm{RC}$ energy transfer and the subsequent primary charge separation in RCs [1]. Some researchers have successfully applied the energy transfer process of photosynthesis to artificial photosynthesis system, such as photoelectrochemical cells based on a bacterial photosynthetic pigment-protein and artificial photosynthetic cell producing energy for protein synthesis $[2,3]$. Up to now, the high-resolution crystal structures of LH2s from Rhodopseudomonas (Rps.) acidophila 10,050 [4] and Rhodospirillum (Rs.) molischianum [5] have been determined. The crystal structures of LH 2 complexes showed that LH2s are nanomeric/octameric assemblies with the heterodimer of repeating $\alpha$ - and $\beta$-apoproteins units. Each $\alpha, \beta$-subunit includes one carotenoid (Crt) and three bacteriochlorophyll $a$ (BChl) molecules. For the LH2 complex of Rps. acidophila, $18 \mathrm{BChl}$ molecules (B850) perpendicular to the membrane plane and excitonically coupled form the ring aggregates, and 9 weakly coupled BChl molecules (B800) parallel to the membrane plane and excitonically coupled form loose ring aggregates. The B800s and B850s binding sites are close to the cytoplasmic and periplasmic of membrane surfaces, respectively. The carotenoid passes in close contact to the edge of the bacteriochlorin ring of a B800 (closest contact $\sim 3.4 \AA$ ). It then passes into the next $\alpha, \beta$ apoprotein pair and runs over the face of the bacteriochlorin ring of the $\alpha$-bound B850 (the closest contact is $\sim 3.7 \AA$ ) [6].

As membrane protein, $\mathrm{LH} 2 \mathrm{~s}$ are generally solubilized in aqueous buffer solution with assistance of detergent for further study. Therefore, the aqueous components, such as detergents (ionic, non-ionic, or zwitterionic), proton, and metal ions, are supposed to influence the properties of pigments embedded in complexes through interacting with the hydrophilic C- or N-terminal domains of LH2 complex, since they are exposed directly to the aqueous phase $[4,7-9]$. The effect of aqueous factors on function of photosynthetic pigment-protein complexes could be observed conveniently through various spectroscopic methods to monitor the conformational change, electronic energy level variation, and excitation dynamics of Crts and BChls.

Some low-molecular-weight (MW) polyols, e.g., glycerol and sorbitol, usually used as bio-preservatives and cryoprotectants, are capable of maintaining structural integrity and activity of (macro) biomolecules in aqueous solution at low temperature, however, they might influence the tertiary or quaternary structures of biomolecules solubilized in it. Many works reported the mechanisms of glycerol affecting watersoluble proteins [10-17], e.g., the glycerol viscosity causing proteins deformation [18], the solvent-accessible surface area of protein [10], the formation of hydrogen-bond network between water and glycerol $[19,20]$, and the access of glycerol to the catalytic site [21]. Concerning the effects of low-molecular-weight polyols on photosynthetic membrane proteins, glycerol addition was found to facilitate $Q_{\mathrm{A}}$-to- $Q_{\mathrm{B}}$ electron transfer and consequently accelerate $P^{+} Q_{\mathrm{B}}{ }^{-}\left(P^{+} Q_{\mathrm{A}}{ }^{-}\right)$ charge recombination through changing protein conformational dynamics in bacterial RCs buffer-detergent solutions $[16,17]$. These studies addressed the critical roles of the hydration shell, composed of the extended hydrogen-bond (HB) network among polyol, residual water, and protein surface residues, in the conformational dynamics and the structural stability of proteins [22, 23].

We have reported the effect of glycerol and sorbitol, as cosolvents, on the embedded pigment's excitation dynamics of LH2 from moderately thermophilic purple bacterium Tch . tepidum, in terms of the interference of hydration status of the whole pigment-protein complexes induced by glycerol and sorbitol [24]. In this study, we intend to examine the effects of glycerol and sorbitol on the hydration status of LH2s from Rba. sphaeroides 2.4.1 in aqueous phase. Rba. sphaeroides 2.4.1 owns acidophila-like LH2 based on their $\alpha, \beta$-apoprotein sequences similarity [25]. We systematically adjusted the volume fractions of glycerol or sorbitol (0-80\%) to tune the water activity around the LH $2 \alpha, \beta$-apoproteins. Accordingly, the spectral changes of both ground-state absorption/fluorescence and triplet excited-state dynamics of the pigment cofactors had been observed. The results are discussed in terms of the water activity effects of C- and $\mathrm{N}$-termini on the relative $\mathrm{BChl}-\mathrm{Crt}$ and $\mathrm{BChl}$ orientations.

\section{Materials and methods}

\subsection{LH2 preparation}

The LH2 was prepared from Rba. sphaeroides 2.4 .1 following the procedures reported in ref [26]. The LH2 preparation in $20 \mathrm{mM}$ Tris- $\mathrm{HCl}$ buffer ( $\mathrm{pH} 7.8$ ) with $0.1 \%$ LDAO was used in the experiments. A series of LH2 samples in $20 \mathrm{mM}$ Tris-HCl buffer ( $\mathrm{pH} 7.8,0.1 \%$ LDAO) with different glycerol or sorbitol contents, $20 \%, 40 \%, 60 \%$, and $80 \%(\mathrm{v} / \mathrm{v})$, were prepared for the subsequent spectroscopic measurements.

\subsection{Steady-state spectroscopy}

Visible-to-near-infrared absorption spectra were recorded on a Cary-50 absorption spectrometer (Varian). Near-infrared fluorescence spectra were recorded on the F-4600 fluorescence spectrometer (Hitachi), whose spectral response sensitivity was calibrated by the use of an HL-2000 CAL radiometric calibration standard (Ocean Optics Inc.). For Raman spectroscopy, the continuous-wave optical excitation at $488 \mathrm{~nm}$ was provided by an $\mathrm{Ar}^{+}$laser (Reliant $300 \mathrm{M}$, Laser Physics Inc.), and the excitation power was $1.5 \mathrm{~mW}$. A backward scattering geometry was used for collecting the scattering light, which was sent to a triple spectrograph (Trivista 
555, Princeton Instruments, USA), and was detected by an intensified CCD detector (ICCD PI-MAX, Princeton Instruments). Before Raman measurements, the $\mathrm{LH} 2$ preparations admixed with glycerol or sorbitol at various fractions were incubated for $6 \mathrm{~h}$. The total exposure time was $100 \mathrm{~s}$ for each measurement. Background spectra were recorded and subtracted from the Raman spectra of the same samples. All measurements were operated at room temperature.

\subsection{Laser flash photolysis}

The excitation pulses at $532 \mathrm{~nm}(1.4 \mathrm{~mJ} /$ pulse, $7 \mathrm{~ns}, 10 \mathrm{~Hz})$ were the second harmonics from a Nd ${ }^{3+}$ :YAG laser (QuantaRay Pro-Series, Spectra Physics Lasers Inc.). The visibleto-near-infrared probe light was provided by a laser-driven white light source (LDLS-EQ-1500, Energetiq), which was sent to a spectrograph (SP2500i, Princeton Instruments, USA). Appropriate optical filters were set in front of the entrance slit to avoid the interference from laser scattering and ambient stray light. The temporal evolution profile of difference absorption $(\triangle \mathrm{OD})$ was recorded with a Si-PIN photodiode (model S3071, Hamamatsu Photonics), and the transient output was fed to a digital storage oscilloscope (bandwidth $600 \mathrm{MHz}$; LeCroy WaveSurfer 64Xs, Chestnut Ridge). The time resolution was $100 \mathrm{~ns}$ as defined by the full width at half maximum (FWHM) of the instrumental response function (IRF). The kinetics trace at a specific probing wavelength was averaged for 250 shots, yielding a $\Delta \mathrm{OD}$ detection sensitivity better than $10^{-4}$. The LH2 preparations in a quartz glass cuvette with optical path length of $1 \mathrm{~cm}$ were adjusted to an optical density of $\mathrm{OD}_{532 \mathrm{~nm}}=0.5$. To remove oxygen, the LH2 samples were bubbled with high purity nitrogen for $30 \mathrm{~min}$ before measurements. The measurements were carried out at room temperature ( $298 \mathrm{~K})$. The least-square curve fitting programs for kinetics analyses were coded based on Matlab 5.2 (Mathworks Inc.).

\section{Results}

\subsection{Resonance Raman spectroscopy}

Resonance Raman spectroscopy is widely used to investigate the conformational change of Crts in solutions and in light-harvesting complexes [1,27-32]. The Crts lie in the hydrophobic environment of membrane, which is apart from the aqueous phase. Moreover, in Rba. sphaeroides 2.4.1 LH2, the main Crts component is spheroidene $\left(n_{\mathrm{C}=\mathrm{C}}=10\right)$ in planar all-trans conformation [33]. Figure 1 shows the resonance Raman spectra of Crts in $R b a$. sphaeroides 2.4.1 LH2 complexes in buffer-detergent
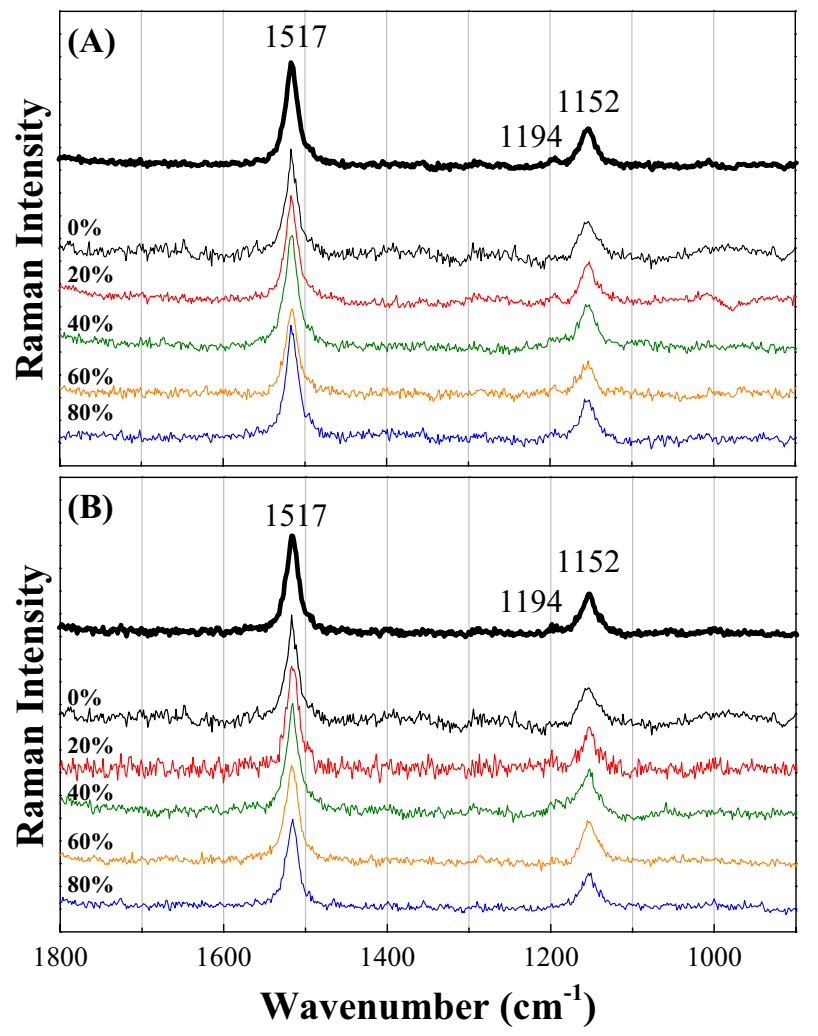

Fig. 1 Resonance Raman spectra of carotenoids in the LH2 complexes from Rba. sphaeroides 2.4.1 in buffer-detergent solutions ( $20 \mathrm{mM}$ Tris- $\mathrm{HCl}, 0.1 \%$ LDAO, $\mathrm{pH}$ 7.8) with the indicated volume fractions of a glycerol and $\mathbf{b}$ sorbitol. Raman excitation wavelength was $488 \mathrm{~nm}(1.5 \mathrm{~mW})$. In each panel, the spectrum shown in thicker black is an average of the Raman spectra under the four different glycerol or sorbitol fractions

solutions with different glycerol and sorbitol volume ratio $(0 \rightarrow 80 \% \mathrm{v} / \mathrm{v})$. The excitation wavelength is $488 \mathrm{~nm}$, which is matched the $\mathrm{S}_{2}\left(1 \mathrm{~B}_{\mathrm{u}}^{+}\right) \leftarrow \mathrm{S}_{0}\left(1 \mathrm{~A}_{\mathrm{g}}{ }^{-}\right)$absorptive transitions of Crts (mainly spheroidene $\left(n_{\mathrm{C}=\mathrm{C}}=10\right)$ ). There are two key Raman lines at $\sim 1517 \mathrm{~cm}^{-1}\left(\nu_{1}\right)$ and $\sim 1152 \mathrm{~cm}^{-1}$ $\left(\nu_{2}\right)$, respectively, meaning the symmetric $\mathrm{C}=\mathrm{C}$ stretching and the $\mathrm{C}-\mathrm{C}$ stretching mixed with $\mathrm{C}-\mathrm{H}$ bending at $\sim 1194 \mathrm{~cm}^{-1}$. The Crts in Rba. sphaeroides $2.4 .1 \mathrm{LH} 2$ remaining all-trans planar conformation could be proved by the lack of the characteristic non-planar twist signal of conjugated backbone [34], i.e., the out-of-plane $\mathrm{C}-\mathrm{H}$ wagging at $\sim 966 \mathrm{~cm}^{-1}$.

In each panel of Fig. 1, both the sum-up spectrum (thicker solid) and each spectrum recorded under the various polyol fractions closely resemble the spectrum of the control $(0 \%)$. Based on this constant Raman mode for all of the samples with various fractions of glycerol or sorbitol mixing, the conclusion that no obvious interference from the addition of these two polyols were performed on Crts conformation could be drawn. 


\subsection{UV-near-infrared absorption and fluorescence spectroscopies}

Considering that glycerol may cause protein degradation at room temperature, steady-state spectroscopic experiments were carried out at different times for glycerol with a high volume ratio $(80 \% \mathrm{v} / \mathrm{v})$ in the sample, as shown in Figure S1 (Supporting Information), it was found that during the course of 2-6 $\mathrm{h}$ after mixing, the sample and glycerol reached a relatively stable state, and the protein was not degraded. In Fig. 2, each absorption spectrum is an average of two independent measurements for the LH2 preparations solubilized for 2 and $6 \mathrm{~h}$, respectively. Due to the constant conformation adopted by Crts in all preparation (proved by Raman measurement and as shown as Fig. 1), the absorption spectra are normalized at the Crt absorption maxima $(\sim 480 \mathrm{~nm}$, Fig. 2). The effects of polyols on the steady-state absorption and fluorescence spectra of $\mathrm{BChl}$ bands are characterized as the following. For steady-state absorption spectra, comparing with the control sample, upon the increase of glycerol and sorbitol fractions from 20 to $80 \% \mathrm{v} / \mathrm{v}$, the Soret band $(\sim 376 \mathrm{~nm})$ and the $Q_{x}$ band $(\sim 590 \mathrm{~nm})$ of BChls change slightly, while the $Q_{y}$ bands of B800 absorption intensity decrease by $22 \%$ and $16 \%$ for glycerol and sorbitol, respectively, the $Q_{y}$ bands of B850 absorption intensity decrease by $8 \%$ and $19 \%$ for glycerol and sorbitol, respectively. The $80 \%$ v/v glycerol causes $\sim 2 \mathrm{~nm}$ red shift for B850 $Q_{y}$ band, $\sim 1 \mathrm{~nm}$ blue shift for B800 $Q_{y}$ band (Fig. 3). These results indicate that glycerol can affect the aggregation condition of both B800 and B850, and sorbitol only affects B800's. Besides,

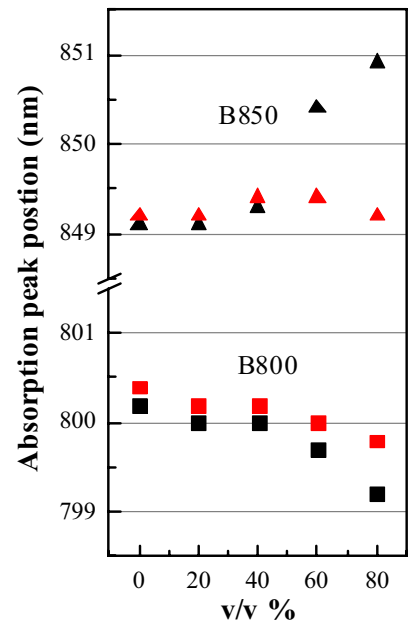

Fig. 3 Steady-state absorption peak position of B800 (square) and B850 (triangle) of the LH2 complexes from Rba. sphaeroides 2.4 .1 in buffer-detergent solutions ( $20 \mathrm{mM}$ Tris- $\mathrm{HCl}, 0.1 \%$ LDAO, $\mathrm{pH}=7.8$ ) with the increased volume fractions of glycerol (black) and sorbitol (red)
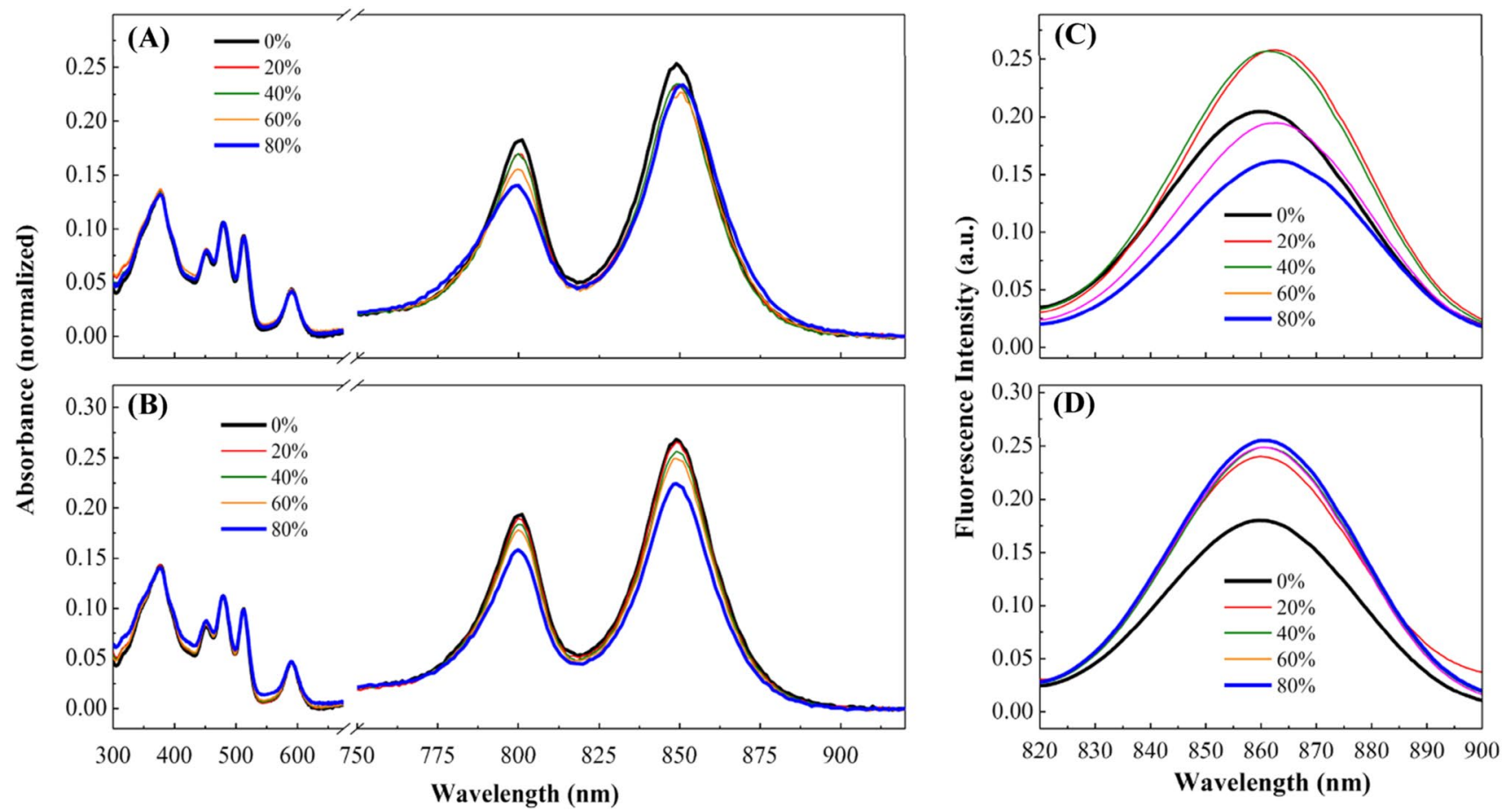

Fig. 2 Steady-state absorption (solid) and fluorescence (dashed) spectra of the LH2 complexes from Rba. sphaeroides 2.4.1 in bufferdetergent solutions $(20 \mathrm{mM}$ Tris- $\mathrm{HCl}, 0.1 \%$ LDAO, $\mathrm{pH}$ 7.8) with the indicated volume fractions of $\mathbf{a}$ glycerol and $\mathbf{b}$ sorbitol. In either panels, the absorption spectra are normalized at the Crt absorption maxima $(480 \mathrm{~nm})$, while the fluorescence spectra are shown without normalization. Fluorescence excitation wavelength was $800 \mathrm{~nm}$ 
we observed that $80 \% \mathrm{v} / \mathrm{v}$ glycerol causes a slight rise of the shorter wavelength side $(<820 \mathrm{~nm})$ of the spectra (Fig. 2a), which comes from the free BChls. Such a rise indicated that the structural intactness of LH2 complexes is broken due to the addition of very high percentage of glycerol. For the fluorescence spectra, when glycerol volume fractions increase from 20 -to- $40 \% \mathrm{v} / \mathrm{v}$, the intensity increase by $\sim 25 \%$, but from 60 -to- $80 \% \mathrm{v} / \mathrm{v}$, decrease by $\sim 21 \%$. When sorbitol volume fractions increase from $20-$ to- $80 \% \mathrm{v} / \mathrm{v}$, the intensity increases by $\sim 40 \%$. The polyol induced spectral changes of the $\mathrm{B} 800$ and $\mathrm{B} 850 \mathrm{Q}_{\mathrm{y}}$ absorption characterized above should be ascribed to the variation in the tertiary structures of the Rba. sphaeroides 2.4.1 LH2 complexes, which might be a result of the water activity changed in solution induced by polyols (see Discussion).

\subsection{Excitation dynamics of Rba. sphaeroides 2.4.1 LH2 complexes in aqueous phase without polyols}

In bacterial photosynthetic pigment-protein complexes, Crt can play photoprotective roles via rapid BChl-toCrt triplet excitation energy transfer (EET). This process occurs in a few nanoseconds and can unitarily quench ${ }^{3} \mathrm{BChl} *$ to avoid the formation of deleterious singlet oxygen $\left({ }^{1} \mathrm{O}_{2} *\right)$ [25, 35]. For Rba. sphaeroides 2.4.1 LH2 complexes, we investigated the triplet excitation dynamics of Crts and BChls without polyols. Used laser flash photolysis with the actinic laser pulses at $532 \mathrm{~nm}$, which corresponding to the $\mathrm{S}_{2}\left(1 \mathrm{~B}_{\mathrm{u}}^{+}\right) \leftarrow \mathrm{S}_{0}\left(1 \mathrm{~A}_{\mathrm{g}}{ }^{-}\right)$transition of Crts. The ultrafast $\operatorname{Crt}\left(\mathrm{S}_{2}\right)$-to-BChl $\left(Q_{x}\right)$ singlet EET processes $(\sim 100 \mathrm{fs})$ account for an overall transfer efficiency $>90 \%$ [36] (whereas the $\operatorname{Crt}\left(\mathrm{S}_{1}\right)$-to-BChl $\left(Q_{y}\right)$ channels of EET are

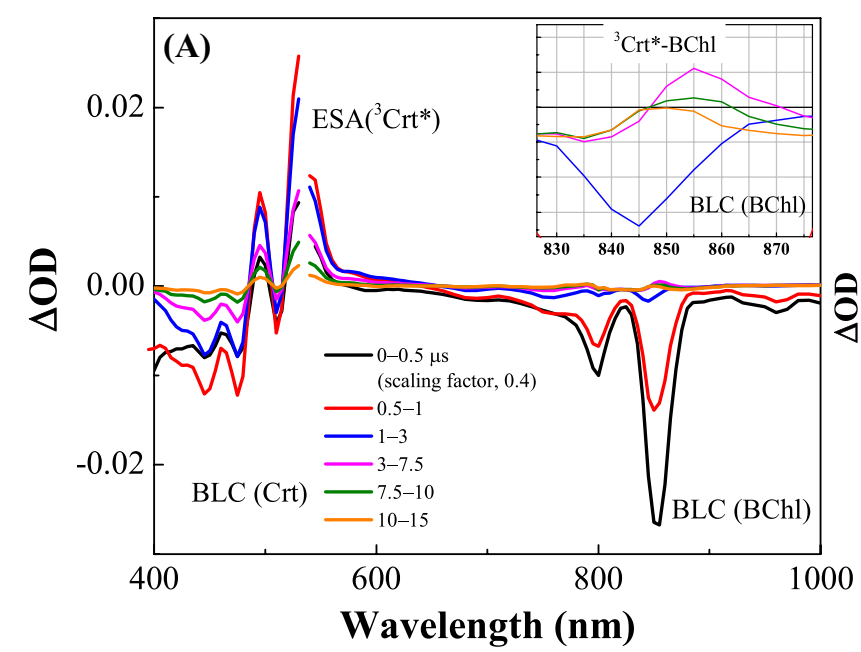

Fig. 4 a Transient spectra for the LH2 complexes from Rba. sphaeroides 2.4 .1 in buffer-detergent solution $(20 \mathrm{mM}$ Tris- $\mathrm{HCl}$, $0.1 \%$ LDAO, $\mathrm{pH} 7.8$ ) without polyol (the control). Inset shows the interrupted for energetics reasons). The subsequent $\mathrm{BChl}$ to-Crt triplet EET takes place within $10 \mathrm{~ns}$, and all of the excitation conversion and EET processes accomplished within the instrumental response time of $100 \mathrm{~ns}$ [37]. The sub-microsecond time-resolved absorption spectra are predominated by the triplet excitations of spheroidene $(n=10)$ in Rba. sphaeroides 2.4.1 LH2 complexes. To enhance the quality of spectral, we divided the whole spectra into some regions. Take the control sample in buffer solutions without polyols as an example (Fig. 4a): (i) Overall photoexcitation induces the ground-state absorption bleaching (BLC) of Crt with maximum vibronic features at $475 \mathrm{~nm}$, shoulder peaks at $445 \mathrm{~nm}$ and $510 \mathrm{~nm}$. Because Crt ESA and BLC come from ${ }^{3} \mathrm{Crt}^{*}$ generated by BChl-to-Crt triplet EET, the main peak of Crt excited-state absorption (ESA) at $530 \mathrm{~nm}$ and shoulder peak at $495 \mathrm{~nm}$ have the same decay time with Crt BLC. (ii) In the initial temporal time regime of $0-0.5 \mu \mathrm{s}, \mathrm{B} 800$ and B850 BLC signals appear at $\sim 800 \mathrm{~nm}$ and $\sim 850 \mathrm{~nm}$, respectively. A negative signal at the region of $920-980 \mathrm{~nm}$ is the red wavelength side of spontaneous B850 fluorescence ( $~ 866 \mathrm{~nm}$, Fig. 2$)$, and the time regime partially coincides with the instrumental response time $(\sim 0.1 \mu \mathrm{s})$. We assigned this negative signal to the stimulated emission of B850. (iii) In the temporal regime of $0.5-1.0 \mu$ s and later, a long time after BChl-to-Crt triplet EET and yielding ${ }^{3} \mathrm{Crt}^{*}$, the distinct B800 and B850 BLC features appear (the inset of Fig. 4a). Compared with the time regime of $0-0.5 \mu \mathrm{s}$, the intensities of B800 and B850 BLC decrease. (iv) In the 3-7.5 $\mu$ s time region (cover the lifetime of ${ }^{3} \mathrm{Cr} t^{*}$ ), a weak $855 \mathrm{~nm}$ ESA accompanied by B850 BLC is shown in the inset of Fig. 4a and farther blowup is in Fig. 4b.

These weak BLC and ESA of BChl are not from free $\mathrm{BChl}$ pigment whose triplet excited state lives in several

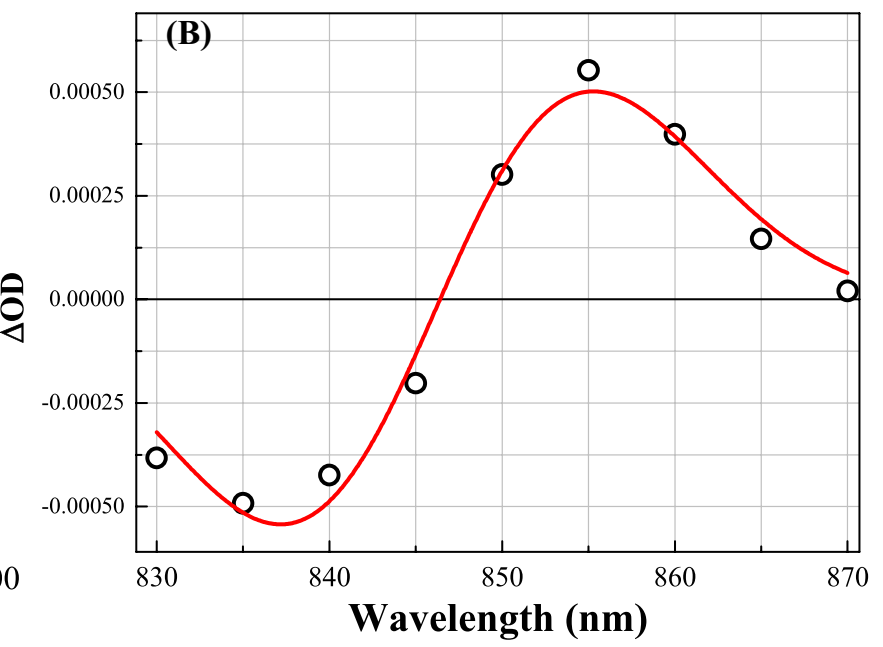

blowup spectra in the near-infrared region. b Transient spectra at 3-7.5 $\mu$ s and the simulated spectrum (red solid. See text for details) 
tens of microseconds. Similar phenomena are observed for Tch. tepidum LH2 excited at Crt directly named interaction bands [38], which suggest originated from the interaction of ${ }^{3} \mathrm{Crt}^{*}$ excitation with the adjacent BChl molecules [4, 18]. Therefore, we ascribed this ESA features to the exciplex-like species owing to the ${ }^{3} \mathrm{Crt}^{*}-\mathrm{BChl}$ electronic coupling. The near-infrared B850 BLC along with the ESA forms a derivative-type spectrum in $830-870 \mathrm{~nm}$ (Fig. 4a, b). This spectral feature could be described by the red-shifted B850 groundstate absorption spectrum $\mathrm{OD}_{\mathrm{B} 850}(\lambda+\delta \lambda)$ to minus the original $\mathrm{B} 850$ ground-state absorption spectrum $\mathrm{OD}_{\mathrm{B} 850}(\lambda)$ using the below equation [24]:

$\Delta \mathrm{OD}_{\text {obs }}(\lambda)=A_{1} \times \mathrm{OD}_{\mathrm{B} 850}(\lambda+\mathrm{d} \lambda)-A_{2} \cdot \mathrm{OD}_{\mathrm{B} 850}(\lambda)$,

where $\delta \lambda$ represents the amount of band shift, and $A_{1}$ and $A_{2}$ are amplitude parameters. The first term of Eq. (1) stems from the dynamic Stark effect of ${ }^{3} \mathrm{Crt} *$ on the adjacent B850 molecules caused B850 ground absorption red shift by $\delta \lambda$, while the second one originated from the depletion of B850 molecules ground absorption spectrum. In this scenario, the size of $\delta \lambda$ can be regarded as a metric of the ${ }^{3} \mathrm{Crt}^{*}-\mathrm{B} 850$ coupling strength, i.e., a larger $\delta \lambda$ implies a stronger coupling. Figure $4 \mathrm{~b}$ exemplifies the simulation of the 3-7.5 $\mu \mathrm{s}$ transient spectrum, which yield B850 ground absorption red shift of $\delta \lambda \approx 12.2 \mathrm{~nm}$ (Table 1). The positive amplitude is slightly larger than the negative one $\left(A_{1} / A_{2} \approx 1.30\right)$, which makes this derivative-type spectrum lightly asymmetric. The dynamic Stark effect between ${ }^{3} \mathrm{Crt} *$ and $\mathrm{B} 850$ induces a redshifted B850 ground-state absorption, which can be used to compare the ${ }^{3} \mathrm{Crt}{ }^{*}-\mathrm{B} 850$ interaction level with solution added glycerol and sorbitol. The weak B800 and B850 BLCs decay corresponding with the ${ }^{3} \mathrm{Crt} *$ ESA/BLC decay time is $\sim 4.5 \mu \mathrm{s}$ (as determined by simultaneously fitting the $\mathrm{Crt}$ kinetics at $475 \mathrm{~nm}$ and $530 \mathrm{~nm}, \mathrm{~B} 800$ and B850 BLC kinetics to a mono-exponential model function, see Table 1 and Figure S2 for details). The lifetime is longer than ${ }^{3} \mathrm{Crt} *$ in Tch. tepidum $\mathrm{LH} 2$ at a similar condition in our previous result (data not shown) [24], because Crt with longer conjugation length has longer ${ }^{3} \mathrm{Crt} *$ lifetime (Crt with $n_{\mathrm{C}=\mathrm{C}}=13$ dominated in Tch. tepidum LH2) [25].

\subsection{Effects of glycerol and sorbitol on the triplet excitation dynamics of Rba. sphaeroides 2.4.1 LH2}

Figure 5 shows the transient spectra of Rba. sphaeroides 2.4.1 LH2 complexes in buffer solution with glycerol or sorbitol in different volume fractions $(40 \%$ and $80 \%$, v/v). See Supporting Information Figure S3 for the other volume fractions ( $20 \%$ and $60 \%, \mathrm{v} / \mathrm{v})$.

Compare the glycerol additions (Fig. 5a, b, 40\% and 80\% $\mathrm{v} / \mathrm{v}$ ) with the control one (Fig. $4 \mathrm{a}, 0 \% \mathrm{v} / \mathrm{v}$ ), the BLC and ESA of Crts in the visible region remain the same, but the interaction bands are highly variable. It is interesting to see that $20 \% \mathrm{v} / \mathrm{v}$ and $80 \% \mathrm{v} / \mathrm{v}$ glycerol led to the disappearance of the ${ }^{3}[\mathrm{Crt} \cdots \mathrm{BChl}]^{*}$ interaction band at $\sim 860 \mathrm{~nm}$ (Fig. 5B, Figure $\mathrm{S} 3 \mathrm{~A})$, Comparing with control one, the ${ }^{3}[\mathrm{Crt} \cdots \mathrm{BChl}] *$ interaction band $(\sim 860 \mathrm{~nm})$ absent at $20 \% \mathrm{v} / \mathrm{v}$ sorbitol, but more prominent upon mixing with other sorbitol volume fractions (Fig. 4a, 0\% v/v, Fig. 5, Figure S3). Besides, glycerol induced slight stronger molecular interactions between ${ }^{3} \mathrm{Crt}$ *

Table 1 Dynamic Stark shifts $(\delta \lambda)$ derived by least-square spectral fitting the interaction bands at $3-7.5 \mu$ s to equation $\Delta \mathrm{OD}_{\mathrm{obs}}(\lambda)=A_{1} \cdot \mathrm{OD}_{\mathrm{B} 850}(\lambda+\delta \lambda)-A_{2} \cdot \mathrm{OD}_{\mathrm{B} 850}(\lambda)$

\begin{tabular}{|c|c|c|c|c|}
\hline \multirow[t]{2}{*}{ Concentration $(\mathrm{v} / \mathrm{v})$} & \multicolumn{4}{|c|}{ Glycerol } \\
\hline & $a_{\mathrm{w}}{ }^{\mathrm{a}}$ & $\delta \lambda(\mathrm{nm})$ & $A_{1} / A_{2}$ & $\tau_{\mathrm{T}}(\mu \mathrm{s})$ \\
\hline $0 \%$ & 1 & $12.23 \pm 1.03$ & 1.30 & $4.48 \pm 0.02$ \\
\hline $20 \%$ & 0.936 & $0.00 \pm 0.00$ & 2.09 & $3.84 \pm 0.03$ \\
\hline $40 \%$ & 0.828 & $14.07 \pm 5.37$ & 1.29 & $4.69 \pm 0.03$ \\
\hline $60 \%$ & 0.683 & $10.75 \pm 3.17$ & 1.12 & $6.11 \pm 0.04$ \\
\hline \multirow[t]{2}{*}{$80 \%$} & 0.399 & $0.00 \pm 0.08$ & 1.05 & $5.65 \pm 0.03$ \\
\hline & \multicolumn{4}{|c|}{ Sorbitol } \\
\hline $20 \%$ & 0.955 & $0.00 \pm 2.23$ & 1.00 & $5.59 \pm 0.02$ \\
\hline $40 \%$ & 0.897 & $12.43 \pm 6.00$ & 0.40 & $5.59 \pm 0.02$ \\
\hline $60 \%$ & 0.843 & $3.03 \pm 0.80$ & 1.15 & $5.49 \pm 0.02$ \\
\hline $80 \%$ & 0.803 & $4.03 \pm 2.36$ & 0.80 & $6.41 \pm 0.02$ \\
\hline
\end{tabular}

The amplitude ratio $A_{1} / A_{2}$ indicates the relative contribution of the dynamic Stark shift to the observed interaction bands (see Supporting Information S4 for details). The triplet excited state lifetime $\left(\tau_{\mathrm{T}}\right)$ of ${ }^{3} \mathrm{Crt}{ }^{*}$ obtained by global fitting of the four kinetics traces including the BLC and ESA of Crts and the BLC of B800 and B850 (see Supporting Information S2 for details), and water activity $\left(a_{\mathrm{w}}\right)$ of the binary solvents at $25^{\circ} \mathrm{C}$, the B800/B850 BLC amplitude ratio $(r)$

${ }^{\mathrm{a}}$ From Reference[39] 

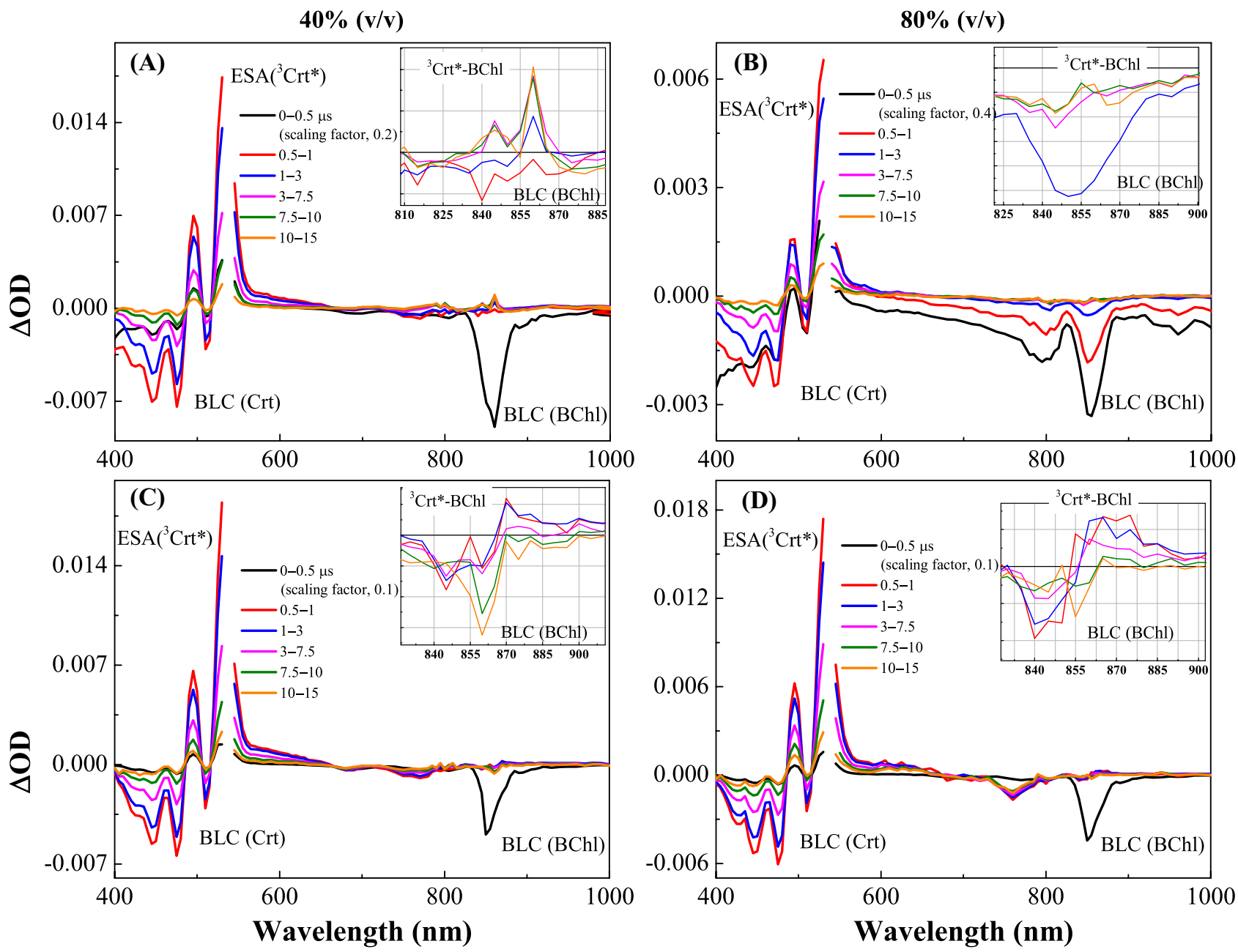

Fig. 5 Transient spectra for the LH2 complexes from Rba. sphaeroides 2.4.1 in buffer-detergent solutions (20 mM Tris-HCl, 0.1\% LDAO, pH 7.8) with the indicated volume fractions of $\mathbf{a}, \mathbf{b}$ glycerol and $\mathbf{c}, \mathbf{d}$ sorbitol. Insets show the blowup spectra in the near-infrared region

and $\mathrm{BChl}(\delta \lambda=11-14 \mathrm{~nm}$ for glycerol and 3-12 $\mathrm{nm}$ for sorbitol (Table 1, Supporting Information Figure S4)). The ${ }^{3} \mathrm{Crt}^{*}$ lifetimes varied in 3.8-6.1 $\mu \mathrm{s}$, showing no clear dependence on the polyol type and volume fractions (Table 1).

\section{Discussion}

The $Q_{y}$ absorption spectra of purple photosynthetic bacteria light-harvest antenna LH2 are susceptible to the ionic properties of detergents, metal ions, temperature, pressure, $\mathrm{pH}$, and grown situations [7, 8, 40-43]. In the present work, we investigated the structure and excitation dynamics of Rba. sphaeroides 2.4.1 LH2 complexes in aqueous phase mixed with glycerol or sorbitol by a series of steady-state and timeresolved spectroscopy. The results show profound variation in the near-infrared absorption and fluorescence spectra of BChls and dynamics of ${ }^{3} \mathrm{Crt}{ }^{*}-\mathrm{BChl}$ interactions upon the addition of glycerol and sorbitol. Based on the steady-state and excited-state spectral properties (dynamics) dependence of polyol concentration and type, the discussion will be focused on the effect of water activity on the C-and N-termini of proteins, which binding with BChls and exposed to the aqueous phase.

\subsection{Hydration susceptible protein-BChl hydrogen-bond strength}

For bacterial LH2 complexes solubilized in buffers, the hydrophobic membrane-spanning section (30-35 $⿱$ ) is surrounded by detergent molecules, while the relatively hydrophilic $\mathrm{C}$ - and $\mathrm{N}$-termini are exposed to the aqueous phase [44, 45], In the case of Rps. acidophila 10050, the high-resolution crystal structures support that the $\mathrm{N}$-terminal domains of LH $2 \alpha, \beta$-apoproteins, embracing $\alpha$-Met $_{-30}$ as the ligand to B800 (Figure S5), are susceptible to hydrostatic pressure or $\mathrm{pH}[9,46]$. For example, under hydrostatic pressure, the $\mathrm{B} 800 Q_{y}$ absorption decreases, which is due 
to the destabilized tertiary or quaternary structures of the $\mathrm{N}$-terminal domains owing to the loss of B800 cofactors and the access of water molecules to the B800 binding motifs. The C-terminal domains of LH $2 \alpha, \beta$-apoproteins, $\alpha-\operatorname{Trp} p_{+14}$, and $\alpha-\mathrm{Tyr}_{+13}$ form stronger $\mathrm{H}$-bindings with $\mathrm{B} 850$, and they are sensitive to environmental change such as basic $\mathrm{pH}$, which makes B850 remarkable spectral blue shift from 852 to $837 \mathrm{~nm}$ in acidophila-like Rhodopseudomonas palustris [41]. Note that the Rba. sphaeroides LH2 is considered to be acidophila-like, the $\alpha, \beta$-apoprotein sequences resemble those of Rps. acidophila LH2 meaning similar B800 or B850 binding motifs between these LH2 complexes (See Supporting Information Figure S5 for a comparison of the LH2 $\alpha, \beta$-apoprotein sequences). The crystal structure of Rps. acidophila $\mathrm{LH} 2$ reveals that there are some hydrogen bonds between the B800 C3 acetyl group and $\beta-\mathrm{Arg}_{-10}$. B850 C3 acetyl groups form hydrogen bonds with $\alpha-\operatorname{Trp}_{+14}$ and $\alpha-\mathrm{Tyr}_{+13}$, respectively. $\mathrm{C} 13^{2}$ ester group forms a weak hydrogen bond with $\alpha-\mathrm{Ala}_{-4}$ [4]. Rba. sphaeroides $2.4 .1 \mathrm{LH} 2$ is acidophila-like and has a similar gene sequence with Rps. acidophila $\mathrm{LH} 2$, which suggests that some similar hydrogen bonds may be present in Rba. sphaeroides 2.4.1 LH2 [47], but $\alpha-\mathrm{Ala}_{-4}$ is replaced by $\alpha-\mathrm{Ser}_{-4}, \alpha-\operatorname{Trp}_{+14}$ is replaced by $\alpha-\mathrm{Tyr}_{+14}$. The above residues almost are weak hydrophobic, which are exquisitely sensitive to the water molecular [48]. Compared with the sequence of Tch. tepidum LH2, the BChls-protein hydrogen bonds are closer to the terminal of protein (Figure S5). The high-resolution neutron scattering analyses have shown that the numbers of water-glycerol hydrogen bonds compensate for the reduction in water-water and glycerol-glycerol hydrogen bonding, and glycerol molecules take the place of water network molecules in the hydrogen-bonded network, then imped the extended water network [19]. The protein hydration interface is disturbed by the hydrogen-bonding network from the bulky water-polyol mixture. The synchrotron radiation wide-angle X-ray scattering analyses have revealed that at glycerol concentrations above $50 \% \mathrm{v} / \mathrm{v}$, the penetration or replacement of glycerol into or with the hydration shell of water molecules surrounding the protein surface appears to depend on the glycerol concentration [49].

It infers that the polyol molecules additions lead to the change of the hydration of proteins, which influence the hydrogen-bond strength between BChls and residues and then affect the characteristics of the steady-state spectrum. In our experiments, glycerol and sorbitol additions changed the $\mathrm{B} 800 \& \mathrm{~B} 850 Q_{y}$ absorption and the fluorescence spectra intensities and peak wavelengths; however, at the same volume fraction, glycerol-water binary solvents showed lower water activity generally [39] (Table 1). Therefore, comparing with sorbitol, glycerol is expected to be more influencing on the hydration status of LH2 complexes. The water activity effects on LH2s can be considered as that the polyol-water hydrogen-bonding network causes a loss of activity water adjacent to the hydration layer of the $\mathrm{N}$-terminal and $\mathrm{C}$-terminal of protein which is close to BChls binding sites.

As the glycerol and sorbitol volume fractions increased from 20 to 40\%, the changes in steady-state absorption and fluorescence-emission were similar. When the glycerol volume fractions reached to $60 \%$ and $80 \%$ volume fraction, the B850 absorption band had experienced $\sim 2 \mathrm{~nm}$ red shift, and fluorescence-emission intensity had declined by $21 \%$ with $\sim 1 \mathrm{~nm}$ red shift. However, $60 \%$ and $80 \%$ v/v sorbitol remained the same fluorescence intensities without red shift. These spectral changes suggest that low water activities can compress the LH2 complexes and enhance molecular interaction among BChls. After all, at the volume fraction of $80 \%$, the water activity of sorbitol solution $(0.803)$ is about twofold of glycerol solution (0.399, Table 1$)$.

\subsection{Hydration susceptible BChl-Crt interaction}

The effective ${ }^{3} \mathrm{Crt}{ }^{*}-\mathrm{BChl}$ interactions fall into van der Waals sphere, and it is sensitive to the BChl-Crt mutual orientation. Adding glycerol and sorbitol altered the shape of ${ }^{3} \mathrm{Cr}{ }^{*}-\mathrm{BChl}$ interaction bands of Rba. sphaeroides 2.4.1 LH2 complexes (Figs. 4, 5, and Figure S3). The resonance Raman spectroscopy had proved that the Crts remained all-trans and planar conformation, so the Crts are essentially unaffected by the water activity change. As discussed above, $\mathrm{BChl}$ binding with protein through hydrogen bond and sensitive to water activity, so the changes in interaction bands spectral are mainly due to the geometrical alteration of BChls relative to Crts.

The dynamic Stark shift $(\delta \lambda)$ of B850 BLC varied with glycerol and sorbitol concentrations change. The sample without polyol caused a band shift of $\delta \lambda \approx 12.2 \mathrm{~nm}$ at long delay time 3-7.5 $\mu \mathrm{s}$. For glycerol and sorbitol additions, the $\delta \lambda$ were 11-14 nm, and 3-12 nm, respectively, shown polyol volume fraction independent. Only the LH2 in 20\%, $80 \% \mathrm{v} / \mathrm{v}$ glycerol and $20 \% \mathrm{v} / \mathrm{v}$ sorbitol solution, the interaction bands vanished (i.e., the ${ }^{3}[\mathrm{Crt} \cdots \mathrm{BChl}]^{*}$ interaction band at $\sim 855 \mathrm{~nm}$ disappeared), which make none band shift of $\delta \lambda \approx 0.0 \mathrm{~nm}$ (Table 1). Besides, the glycerol additions have a bit larger $A_{1} / A_{2}$. However, the mechanism behind this phenomenon remains to be explored. A plain conjecture is that glycerol and sorbitol have different molecular weight, may cause different effects on the water hydrogen-bond network, then form different polyol-water and polyol-protein hydrogen-bond patterns, which led to different effects on $\mathrm{BChl}$ orientations change. Here, we note that the changes of intriguing fluorescence intensity can be connected to the drastic decrease of water activity. Glycerol addition with lower water activity reduces the fluorescence intensity. After all, research has shown that under $80 \%$ molar fraction of glycerol, majority water molecules exist as monomers owing 
to the strong hydrogen bonding to glycerol, so the original hydrogen-bonded network of water is disrupted [50]. However, the refined explanation about this phenomenon effect on protein and binding BChls needs more elaborate experiments.

\section{Conclusions}

Used steady-state optical spectroscopies and sub-microsecond laser flash photolysis, we investigated the impacts of glycerol and sorbitol on the near-infrared absorption/fluorescence, and the triplet excitation dynamics of the detergent-solubilized Rba. sphaeroides 2.4.1 LH2 complexes. The BChl $Q_{y}$ absorption/fluorescence experienced changes in glycerol and sorbitol additions, which correlated to the effect of water activities of the water-polyol binary solvents on the hydration status of the $\mathrm{LH} 2 \mathrm{C}$ - and N-termini. The dynamic spectra of the ${ }^{3} \mathrm{Crt}{ }^{*}-\mathrm{BChl}$ interaction bands were found been influenced by glycerol and sorbitol additions, which were interpreted to BChl-Crt orientation respond to polyols addition. The Rba. sphaeroides 2.4.1 LH2 are found to retain the photoprotective functionality via efficient BChl-to-Crt triplet excitation energy transfer, and reference the thermophiles purple bacterium Tch. tepidum, Rba. sphaeroides 2.4.1 LH2 is more sensitive to low-molecularweight polyols.

Supplementary Information The online version contains supplementary material available at https://doi.org/10.1007/s43630-021-00046-6.

Funding This research was funded by the Natural Science Foundation of China Research (22063006; 22073113), and the Foundation of Baotou teachers' College for High-Level Talents Introduction (01108022/023).

\section{Declarations}

Conflict of interest The authors declare no conflict of interest.

\section{References}

1. Tonouchi, N., Kosumi, D., Sugisaki, M., Nango, M., \& Hashimoto, H. (2015). How do surrounding environments influence the electronic and vibrational properties of spheroidene? Photosynthesis Research, 124(1), 77-86

2. Singh, V. K., Ravi, S. K., Ho, J. W., Wong, J. K., Jones, M. R., \& Tan, S. C. (2017). Biohybrid photoprotein-semiconductor cells with deep-lying redox shuttles achieve a $0.7 \mathrm{~V}$ photovoltage. Advanced Functional Materials., 28, 1703689-1703697

3. Berhanu, S., Ueda, T., \& Kuruma, Y. (2019). Artificial photosynthetic cell producing energy for protein synthesis. Nature Communications, 10(1), 1325-1335

4. Papiz, M. Z., Prince, S. M., Howard, T., Cogdell, R. J., \& Isaacs, N. W. (2003). The structure and thermal motion of the B800-850 LH2 complex from Rps acidophila at $2.0 \AA$ resolution and $100 \mathrm{~K}$ :
New structural features and functionally relevant motions. Journal of Molecular Biology., 326(5), 1523-1538

5. Koepke, J., Hu, X., Muenke, C., Schulten, K., \& Michel, H. (1996). The crystal structure of the light-harvesting complex II (B800-850) from Rhodospirillum molischianum. Structure., 4(5), $581-597$

6. Cogdell, R. J., Gall, A., \& Köhler, J. (2006). The architecture and function of the light-harvesting apparatus of purple bacteria: From single molecules to in vivo membranes. Quarterly Reviews of Biophysics, 39(3), 227-324

7. Sekine, F., Horiguchi, K., Kashino, Y., Shimizu, Y., Yu, L. J., Kobayashi, M., \& Wang, Z. Y. (2012). Gene sequencing and characterization of the light-harvesting complex 2 from thermophilic purple sulfur bacterium Thermochromatium tepidum. Photosynthesis Research, 111(1-2), 9-18

8. Shi, Y., Zhao, N. J., Wang, P., Fu, L. M., Yu, L. J., Zhang, J. P., \& Wang-Otomo, Z. Y. (2015). Thermal Adaptability of the light-harvesting complex 2 from Thermochromatium tepidum: Temperature-Dependent excitation transfer dynamics. The Journal of Physical Chemistry B, 119(47), 14871-14879

9. Gall, A., Ellervee, A., Sturgis, J. N., Fraser, N. J., Cogdell, R. J., Freiberg, A., \& Robert, B. (2003). Membrane protein stability: High pressure effects on the structure and chromophore-binding properties of the light-harvesting complex LH2. Biochemistry, 42(44), 13019-13026

10. Ghattyvenkatakrishna, P. K., \& Carri, G. A. (2014). Effect of glycerol-water binary mixtures on the structure and dynamics of protein solutions. Journal of Biomolecular Structure \& Dynamics, 32(3), 424-437

11. Renger, T., Trostmann, I., Theiss, C., Madjet, M. E., Richter, M., Paulsen, H., Eichler, H. J., Knorr, A., \& Renger, G. (2007). Refinement of a structural model of a pigment-protein complex by accurate optical line shape theory and experiments. The Journal of Physical Chemistry B, 111(35), 10487-10501

12. Theiss, C., Trostmann, I., Andree, S., Schmitt, F. J., Renger, T., Eichler, H. J., Paulsen, H., \& Renger, G. (2007). Pigment-pigment and pigment-protein interactions in recombinant water-soluble chlorophyll proteins (WSCP) from cauliflower. The Journal of Physical Chemistry B, 111(46), 13325-13335

13. Schmitt, F. J., Trostmann, I., Theiss, C., Pieper, J., Renger, T., Fuesers, J., Hubrich, E. H., Paulsen, H., Eichler, H. J., \& Renger, G. (2008). Excited state dynamics in recombinant water-soluble chlorophyll proteins (WSCP) from cauliflower investigated by transient fluorescence spectroscopy. The Journal of Physical Chemistry B, 112(44), 13951-13961

14. Hussels, M., \& Brecht, M. (2011). Evidence for direct binding of glycerol to photosystem I. FEBS Letters, 585(15), 2445-2449

15. Krieger, A., Rutherford, A. W., \& Jegerschold, C. (1998). Thermoluminescence Measurements on chloride-depleted and calciumdepleted photosystem II. Biochimica et Biophysica Acta, 1364(1), $46-54$

16. Palazzo, G., Francia, F., Mallardi, A., Giustini, M., Lopez, F., \& Venturoli, G. (2008). Water Activity regulates the $\mathrm{Q}_{\mathrm{A}}{ }^{-}$to $\mathrm{Q}_{\mathrm{B}}$ electron transfer in photosynthetic reaction centers from Rhodobacter sphaeroides. Journal of the American Chemical Society, 130(29), 9353-9363

17. Savitsky, A., Malferrari, M., Francia, F., Venturoli, G., \& Möbius, K. (2010). Bacterial photosynthetic reaction centers in trehalose glasses: Coupling between protein conformational dynamics and electron-transfer kinetics as studied by laser-flash and highfield Epr spectroscopies. The Journal of Physical Chemistry B, 114(39), 12729-12743

18. Sampedro, J. G., \& Uribe, S. (2004). Trehalose-enzyme interactions result in structure stabilization and activity inhibition. The role of viscosity. Molecular and Cellular Biochemistry, 256257(1-2), 319-327 
19. Towey, J. J., \& Dougan, L. (2012). Structural examination of the impact of glycerol on water structure. The Journal of Physical Chemistry B, 116(5), 1633-1641

20. Mehrnejad, F., Ghahremanpour, M. M., Khadem-Maaref, M., \& Doustdar, F. (2011). Effects of osmolytes on the helical conformation of model peptide: Molecular dynamics simulation. The Journal of Chemical Physics, 134(3), 035104

21. Miyazaki, T., Yoshida, M., Tamura, M., Tanaka, Y., Umezawa, K., Nishikawa, A., \& Tonozuka, T. (2013). Crystal structure of the $\mathrm{N}$-terminal domain of a glycoside hydrolase family 131 protein from Coprinopsis Cinerea. FEBS Letters, 587(14), 2193-2198

22. Malferrari, M., Francia, F., \& Venturoli, G. (2011). Coupling between electron transfer and protein-solvent dynamics: FTIR and laser-flash spectroscopy studies in photosynthetic reaction center films at different hydration levels. The Journal of Physical Chemistry B, 115(49), 14732-14750

23. Malferrari, M., Francia, F., \& Venturoli, G. (2015). Retardation of protein dynamics by trehalose in dehydrated systems of photosynthetic reaction centers. Insights from electron transfer and thermal denaturation kinetics. The Journal of Physical Chemistry B, 119(43), 13600-13618

24. Shi, Y., Yu, J., Yu, L. J., Wang, P., Fu, L. M., Zhang, J. P., \& Wang-Otomo, Z. Y. (2017). Dependence of the hydration status of bacterial light-harvesting complex 2 on polyol cosolvents. Photochemical \& Photobiological Sciences, 16(5), 795-807

25. Kakitani, Y., Akahane, J., Ishii, H., Sogabe, H., Nagae, H., \& Koyama, Y. (2007). Conjugation-length dependence of the $T_{1}$ lifetimes of carotenoids free in solution and incorporated into the LH2, LH1, RC, and RC-LH1 complexes: Possible mechanisms of triplet-energy dissipation. Biochemistry, 46(8), 2181-2197

26. Novoderezhkin, V. I., Cohen Stuart, T. A., \& van Grondelle, R. (2011). Dynamics of exciton relaxation in LH2 antenna probed by multipulse nonlinear spectroscopy. Journal of Physical Chemistry A, 115(16), 3834-3844

27. Ma, F., Kimura, Y., Yu, L. J., Wang, P., Ai, X. C., Wang, Z. Y., \& Zhang, J. P. (2009). Specific $\mathrm{Ca}^{2+}$-binding motif in the LH1 complex from photosynthetic bacterium Thermochromatium tepidum as Revealed by optical spectroscopy and structural modeling. FEBS Journal, 276(6), 1739-1749

28. Kimura, Y., Inada, Y., Numata, T., Arikawa, T., Li, Y., Zhang, J. P., Wang, Z. Y., \& Ohno, T. (2012). Metal cations modulate the bacteriochlorophyll-protein interaction in the light-harvesting 1 core complex from Thermochromatium tepidum. Biochimica et Biophysica Acta, 1817(7), 1022-1029

29. Qian, P., Saiki, K., Mizoguchi, T., Hara, K., Sashima, T., Fujii, R., \& Koyama, Y. (2001). Time-dependent changes in the carotenoid composition and preferential binding of spirilloxanthin to the reaction center and anhydrorhodovibrin to the LH1 antenna complex in Rhodobium marinum. Photochemistry and Photobiology, 74(3), 444-452

30. Gall, A., Henry, S., Takaichi, S., Robert, B., \& Cogdell, R. J. (2005). Preferential incorporation of coloured-carotenoids occurs in the LH2 complexes from non-sulphur purple bacteria under carotenoid-limiting conditions. Photosynthesis Research, 86(1-2), $25-35$

31. Kimura, Y., Kasuga, S., Unno, M., Furusawa, T., Osoegawa, S., Sasaki, Y., Ohno, T., \& Wang-Otomo, Z. Y. (2015). The roles of C-terminal residues on the thermal stability and local Heme environment of cytochrome C' from the thermophilic purple sulfur bacterium Thermochromatium tepidum. Photosynthesis Research, 124(1), 19-29

32. Limantara, L., Fujii, R., Zhang, J. P., Kakuno, T., Hara, H., Kawamori, A., Yagura, T., Cogdell, R. J., \& Koyama, Y. (1998). Generation of triplet and cation-radical bacteriochlorophyll a in carotenoidless LH1 and LH2 antenna complexes from Rhodobacter sphaeroides. Biochemistry, 37(50), 17469-17486
33. Desamero, R. Z. B., Chynwat, V., van der Hoef, I., Jansen, F. J., Lugtenburg, J., Gosztola, D., Wasielewski, M. R., Cua, A., Bocian, D. F., \& Frank, H. A. (1998). Mechanism of energy transfer from carotenoids to bacteriochlorophyll: Light-harvesting by carotenoids having different extents of $\Pi$-electron conjugation incorporated into the b850 antenna complex from the carotenoidless bacterium Rhodobacter sphaeroides R-26.1. The Journal of Physical Chemistry B, 102(42), 8151-8162

34. Papagiannakis, E., Das, S. K., Gall, A., van Stokkum, I. H. M., Robert, B., van Grondelle, R., Frank, H. A., \& Kennis, J. T. M. (2003). Light harvesting by carotenoids incorporated into the B850 light-harvesting complex from Rhodobacter sphaeroides R-26.1: Excited-state relaxation, ultrafast triplet formation, and energy transfer to bacteriochlorophyll. The Journal of Physical Chemistry B, 107(23), 5642-5649

35. Alric, J. (2005). In vivo carotenoid triplet formation in response to excess light: A supramolecular photoprotection mechanism revisited. Photosynthesis Research, 83(3), 335-341

36. Cong, H., Niedzwiedzki, D. M., Gibson, G. N., LaFountain, A. M., Kelsh, R. M., Gardiner, A. T., Cogdell, R. J., \& Frank, H. A. (2008). Ultrafast time-resolved carotenoid to-bacteriochlorophyll energy transfer in LH2 complexes from photosynthetic bacteria. The Journal of Physical Chemistry B, 112(34), 10689-10703

37. Yang, F., Yu, L. J., Wang, P., Ai, X. C., Wang, Z. Y., \& Zhang, J. P. (2010). Excitation dynamics of the light-harvesting complex 2 from Thermochromatium tepidum. Acta Physica Sinica, 26(07), 2021-2030

38. Niedzwiedzki, D. M., Kobayashi, M., \& Blankenship, R. E. (2011). Triplet excited state spectra and dynamics of carotenoids from the thermophilic purple photosynthetic bacterium Thermochromatium tepidum. Photosynthesis Research, 107(2), 177-186

39. Ninni, L., Camargo, M. S., \& Meirelles, A. J. A. (2000). Water activity in polyol systems. Journal of Chemical and Engineering Data, 45(4), 654-660

40. Moulisová, V., Luer, L., Hoseinkhani, S., Brotosudarmo, T. H., Collins, A. M., Lanzani, G., Blankenship, R. E., \& Cogdell, R. J. (2009). Low light adaptation: Energy transfer processes in different types of light harvesting complexes from Rhodopseudomonas palustris. Biophysical Journal, 97(11), 3019-3028

41. Feng, J., Li, X., \& Liu, Y. (2008). Effects of pH on the peripheral light-harvesting antenna complex for Rhodopseudomonas palustris. Science in China. Series C, Life Sciences, 51(8), 760-766

42. Sturgis, J. N., \& Niedermann, R. A. (1996). The Effect of different levels of the B800-850 light-harvesting complex on intracytoplasmic membrane development in Rhodobacter sphaeroides. Archives of Microbiology, 165(4), 235-242

43. Reddy, N. R., Wu, H. M., Jankowiak, R., Picorel, R., Cogdell, R. J., \& Small, G. J. (1996). High pressure studies of energy transfer and strongly coupled bacteriochlorophyll dimers in photosynthetic protein complexes. Photosynthesis Research, 48(1-2), 277-289

44. Hong, X., Weng, Y. X., \& Li, M. (2004). Determination of the topological shape of integral membrane protein light-harvesting complex LH2 from photosynthetic bacteria in the detergent solution by small-angle X-ray scattering. Biophysical Journal, 86(2), 1082-1088

45. Prince, S. M., Howard, T. D., Myles, D. A., Wilkinson, C., Papiz, M. Z., Freer, A. A., Cogdell, R. J., \& Isaacs, N. W. (2003). Detergent structure in crystals of the integral membrane light-harvesting complex LH2 from Rhodopseudomonas acidophila strain 10050. Journal of Molecular Biology, 326(1), 307-315

46. Kangur, L., Timpmann, K., \& Freiberg, A. (2008). Stability of integral membrane proteins under high hydrostatic pressure: The LH2 and LH3 antenna pigment-protein complexes from photosynthetic bacteria. The Journal of Physical Chemistry B, 112(26), 7948-7955 
47. Swainsbury, D. J. K., Faries, K. M., Niedzwiedzki, D. M., Martin, E. C., Flinders, A. J., Canniffe, D. P., Shen, G., Bryant, D. A., Kirmaier, C., Holten, D., \& Hunter, C. N. (2019). Engineering of B800 bacteriochlorophyll binding site specificity in the Rhodobacter aphaeroides LH2 antenna. Biochimica et Biophysica Acta, Bioenergetics, 1860(3), 209-223

48. Rego, N. B., Xi, E., \& Patel, A. J. (2019). Protein hydration waters are susceptible to unfavorable perturbations. Journal of the American Chemical Society, 141(5), 2080-2086
49. Hirai, M., Ajito, S., Sugiyama, M., Iwase, H., Takata, S. I., Shimizu, N., Igarashi, N., Martel, A., \& Porcar, L. (2018). Direct evidence for the effect of glycerol on protein hydration and thermal structural transition. Biophysical Journal, 115(2), 313-327

50. Towey, J. J., Soper, A. K., \& Dougan, L. (2011). Preference for isolated water molecules in a concentrated glycerol-water mixture. The Journal of Physical Chemistry B, 115(24), 7799-7807

\section{Authors and Affiliations}

\section{Ying Shi ${ }^{1}$ - Jie Yu ${ }^{3} \cdot$ Yu-Chen Liu ${ }^{4} \cdot$ Peng Wang ${ }^{2}$ · Jian-Ping Zhang ${ }^{2}$}

1 Department of Chemistry, Baotou Teachers' College, Baotou 014030, People's Republic of China

2 Department of Chemistry, Renmin University of China, Beijing 100872, People's Republic of China
3 College of Pharmacy, Weifang Medical University, Weifang 261042, People's Republic of China

4 Division of Chemical Physics, Department of Chemistry, Lund University, Box 124, 22100 Lund, Sweden 